\title{
El Juez Constitucional como Legislador Positivo en el Perú
}

Fernán Altuve-Febres Lores

Artículo recibido: 08/04/2010 Aprobado: 31/05/2010

faltuve@estudioafd.com

\section{RESUMEN}

La Constitución Política del Perú es una Carta política abierta a la posibilidad de que sea reformada observando los parámetros establecidos en el mismo articulado. De igual forma es una Carta de derechos que guarda la posibilidad de ser utilizada para la protección de las libertades políticas y, sobre todo, que imponga límites o parámetros a la actuación libre y discrecional del legislador. Entre los sujetos que pueden interpretar la Constitución se encuentra el Tribunal Constitucional, órgano jurisdiccional superior que se encarga de interpretar o dotar de contenido a los valores constitucionales. El presente artículo describe la forma como el juez constitucional peruano actúa como legislador positivo cuando expide sentencias interpretativas; precedentes vinculantes crean doctrina jurisprudencial, pues ello implicaría el ejercicio real de facultades legislativas (legislador positivo).

\section{ABSTRACT}

The Constitution of Peru is open to the possibility that it is reformed within the parameters laid out in the articles. Likewise, a Bill of Rights that holds the possibility of being used for the protection of political freedoms and, above all, to impose limits or parameters of free and discretionary action by the legislature. Among subjects who can interpret the Constitution is the Constitutional Court, the highest court in charge of interpreting or provide content to constitutional values. This article describes how the Peruvian constitutional court acts as a positive legislator when issuing statements interpretative jurisprudence creates binding precedent, because they involve the actual exercise of legislative powers (legislature positive).

\section{PALABRAS CLAVE}

Justicia constitucional, legislador positivo, Tribunal Constitucional del Perú, interpretación constitucional.

\section{KEYWORDS}

Constitutional Justice, positive legislator, Constitutional Court, constitutional interpretation.

\section{EL CARACTER ABIERTO DE LA CONSTITUCIÓN POLÍTICA DEL PERÚ}

La Constitución Política del Perú se ha definido como una constitución democrática, esto es, una constitución abierta a la posibilidad de que sea revisada siempre y cuando se sigan los cauces procedimentales establecidos en ella misma, a la posibilidad que sea utilizada frente a las libertades políticas $y$, sobre todo, que imponga limites 0 parámetros a la actuación libre y discrecional del legislador.

Sobre el particular, los límites que impone una constitución democrática, en la práctica, es una tarea compleja, pues en las ultimas décadas se ha

${ }^{1}$ Máster en Historia y doctorado en filosofía de la Universidad Nacional Mayor de San Marcos (Perú). Catedrático de Historia del Derecho Romano y Relaciones Internacionales en la Universidad de Lima (Perú). 
ido recogiendo al interior de ésta principios, valores y derechos, que no sólo son límites, sino mandatos de actuación positiva a los poderes públicos; por lo que existe el riesgo que la constitución se convierta de un mero marco o limite a un programa de determinación de las actividades legislativas. Y, lo extremo seria, según Díaz Revorio: ${ }^{2}$

“(...) el legislador asuma la función de ser un mero desarrollador o aplicador de la Constitución y, por su parte, que el Tribunal Constitucional, con su última palabra en materia de interpretación constitucional, termine porcrear Derecho".

En ese sentido, resulta lógico sostener que la interpretación constitucional se encuentra claramente determinada por el carácter de la Constitución. Ello, en la medida que la interpretación sería diferente si se entiende a la constitución como un mero marco o límite 0 , por otro lado, como si fuera un programa de actuación positiva.

En este orden de ideas, desde hace varias décadas se inició un debate en la doctrina norteamericana en torno a la relación que existe entre el grado de apertura constitucional y la forma como se interpretan las normas constitucionales, lo que a su vez, se dividía en tres aspectos: por un lado, la tensión entre interpretativismo y no interpretativismo; en segundo lugar, la polémica entre el activismo o la restricción judicial $y$; finalmente, la elección entre valores sustantivos 0 adjetivos en la interpretación constitucional. ${ }^{3}$

Respecto al "interpretativismo", esto significa que la constitución tiene un significado por lo que no es posible acudir a fuentes extra constitucionales $y$, en esa medida, el juzgador solo podrá ceñirse a aplicar la norma manifiesta o claramente implícita en la Constitución y; por su parte, el "no interpretativismo" se refiere a que la constitución contiene una serie de disposiciones vagas e imprecisas de las que no se puede encontrar la solución a los problemas constitucionales, por lo que los tribunales deberán buscar las soluciones fuera del texto constitucional.

Con relación al segundo aspecto del debate jurisprudencial norteamericano, se puede señalar que "restricción" judicial significa que la función del juez se limita a interpretar la norma en sentido estricto, sin que tenga la posibilidad de crear 0 construir normas. Y, por el contrario, el "activismo" requiere una participación activa del juzgador para defender los valores constitucionales, pudiendo llegar hasta la creación de normas.

Finalmente, la interpretación basada en la existencia de "valores sustantivos" supone que el juez tenga un margen de actuación bastante limitada, mientras que la basada en "valores adjetivos", al contrario, permite al juez actuar de manera amplia y discrecional.

Si bien, el debate doctrinario no ha logrado uniformizar las posiciones sobre la relación que existe entre la constitución abierta y su forma de interpretarla, ha permitido que se entienda a la Constitución como una norma a la que no se puede interpretar como cualquier otra del sistema jurídico $y$, en ese sentido, cuando existe la tarea de dotar de contenido a un concepto constitucional no sólo se debe tener en cuenta criterios interpretativos como: literal, histórico, sistemático, teleológico, entre otros; sino y, sobre todo, se deberá tener en cuenta el contenido mínimo o básico de los tres pilares de la democracia: libertad, igualdad y justicia, los mismos que si bien se encuentran sujetos a cierta variación por el transcurso del tiempo, se encuentran limitados mínimamente por la Historia y el propio lenguaje. En base a la conjunción de los referidos criterios o pautas, el Tribunal Constitucional deberá establecer la constitucionalidad de las leyes y, a su vez, oponerse a las obras del legislador cuando esta colisione frontalmente con las concepciones generalmente admitidas.

${ }^{2}$ DIAZ REVORIO, Francisco Javier. La Constitución Abierta y su Interpretación. Palestra Editores. Lima. 2004. P. 21.

${ }^{3}$ Óp. Cit. P. 163. 
En otras palabras, conforme lo sostiene Díaz Revorio: ${ }^{4}$

"(...) la presencia de los valores superiores en la Constitución aumenta su discrecionalidad, y da base constitucional a un cierto poder $<<$ creativo $>>$, tanto en el sentido de permitir $<<$ completar $\gg>$ los preceptos constitucionales $y<<r e l l e n a r>>$ sus posibles vacios, como en el sentido más estricto de poder <<reconocer>> nuevos derechos fundamentales. Sin embargo, esta labor $<<$ creativa >>, cuando sea necesaria, siempre ha de tener como base la Norma fundamental, cuyo texto ha de ser interpretado basándose tanto en los criterios interpretativos <<comunes $>>$ como en los especificos. En esta labor, es importante el uso de la razón (lógica) y, desde luego, el Tribunal ha de tener presente cuál es el <<consenso >> o idea socialmente admitida de los valores constitucionales. En nuestro sistema, el consenso social o idea generalmente admitida porla sociedad actuará como un elemento o criterio interpretativo entre otros, pero no puede propugnarse como el elemento <<principal >> para <<llenar de contenido $>$ a los valores, puesto que este elemento principal es en nuestro sistema el propio texto constitucional, que desarrolla el contenido de los propios valores. Con todo, la importancia del consenso social no es despreciable, ya que, junto a los demás criterios, siempre está presente a la hora de interpretar los valores".

En este orden de ideas, podemos sostener que la interpretación de la Norma Fundamental estará supeditada íntimamente al propio carácter de la Constitución que defiende y, en la medida que ésta contenga gran cantidad de principios y valores fundamentales, expresados de manera general e imprecisa, permitirá diversas opciones para el intérprete.

De esta manera, ingresamos al terreno del intérprete constitucional, quien en primera instancia, vendría a ser el legislador y, en segunda instancia, el Tribunal Constitucional. No obstante, en la práctica, la distancia que debiera existir entre ambos interpretes se ve reducida, ya que el legislador tiende a dejar de ser un poder absolutamente discrecional, como consecuencia de ser el representante de la soberanía popular, para convertirse en un órgano desarrollador de las normas constitucionales y, por su parte, el Tribunal Constitucional tiende a dejar de ser el órgano que limita o establece el marco jurídico - constitucional de los poderes del estado para transformarse en un órgano que realiza una labor creativa de derecho constitucional.

En otras palabras, el problema se resume en que el legislador tiende a pasar de creador a aplicador del Derecho y, el Tribunal Constitucional, de aplicador a creador; problema latente y controversial en nuestro sistema jurídico constitucional.

\section{LAINTERPRETACIÓN CONSTITUCIONAL}

Interpretar significa encontrar 0 descifrar el significado de las palabras o textos. Esta idea también se tiene en cuenta cuando se refiere a la interpretación jurídica, con la particularidad de que se trata de una norma, la misma que podría ser entendida como mandato o prohibición dirigido a los poderes públicos 0 a ciudadanos, cuyo incumplimiento acarrea consecuencias 0 sanciones jurídicas. Al respecto, Rubio Correa sostiene que los métodos de la interpretación constitucional son procedimientos a través de los cuales se desentraña el significado de las normas jurídicas.

Un elemento que no se puede dejar de mencionar, al referirnos al proceso de interpretación jurídica, es la diferencia que existe entre "descubrir" el contenido de la norma preexistente y "atribuir" a dicha norma un significado normativo, pues en esta última entraríamos al terreno de la creación del derecho. Aunque este tema reviste una gran complejidad, por lo que resulta ambicioso abordarlo a plenitud en estas líneas, no cabe duda que en todo proceso interpretativo - a menos que la norma

${ }^{4}$ Op.Cit. P. 227-228.

${ }^{5}$ RUBIO CORREA, Marcial. La Interpretación de la Constitución según el Tribunal Constitucional. Fondo Editorial de la Pontificia Universidad Católica del Perú. Lima. 2005. P. 417. 
se encuentre enunciada de manera clara e evidente- existe una cierta cuota de creatividad, la que implicaría la creación de nuevo Derecho, en caso, dicha interpretación sea realizada por los tribunales que tengan dicha facultad.

Ahora bien, como se ha sostenido, la Constitución por ser la Norma Fundamental que contiene rasgos o particularidades desde el punto de vista de su rango, contenido y finalidad, su interpretación también reviste de ciertas particularidades al aplicarse los métodos o criterios de interpretación jurídica general.

Y, en ese mismo sentido, el Tribunal Constitucional ha señalado lo siguiente:

“(...)4. Previamente al análisis hermenéutico del modelo económico constitucional, conviene precisar que si bien es posible aplicar a la Norma Fundamental los criterios interpretativos propiamente aplicables a las normas de rango legal (a saber, los métodos literal, sistémico, histórico y sociológico), no es menos cierto que la Constitucional posee también un importante contenido político, dado que incorpora no sólo reglas imperativas de exigencia o eficacia inmediata o auto aplicativa, sino también un cúmulo de disposiciones que propugnan el <<programa social $\gg$ del Estado, en una de cuyas vertientes principales se sitúa el régimen económico constitucional. Se trata pues, en buena cuenta, de la distinción a la que alude Robert Alexy, cuando subraya la existencia de <<normas constitucionales regla $>>$ y $<<$ normas constitucionales principio $>>$ (Teoría de los Derechos Fundamentales. Madrid: Centro de estudios Políticos y Constitucionales, segunda reimpresión, 2001).

Entonces, a los clásicos criterios de interpretación, deben sumarse aquellos que permitan concretar de mejor manera los principios que inspiran los postulados político-sociales y político-económicos de la Carta. Por ello la pertinencia en proceder, por una parte, a una interpretación institucional de sus clausulasy, por otra, a una social". 6
Por consiguiente, se puede concluir que los métodos de interpretación jurídica en general, también pueden aplicarse en el ámbito constitucional pero teniendo en cuenta los principios y criterios de interpretación específica, esto es, la constitucional. Así, los métodos generales 0 tradicionales que tenemos para interpretar la Constitución son: literal, sistémico, histórico, sociológico y de ratio leguis. El método literal 0 , también denominado gramatical, se sostiene en la idea del "sentido propio de las palabras" y, aunque en aquellos casos en los que la dicción literal es clara y precisa, la interpretación literal resulta siendo la más segura; este método es en sí mismo insuficiente, pues una norma constitucional forma parte de todo un sistema, el cual debe ser comprendido dentro de éste; además que, son pocos los términos o dispositivos claros y precisos.

El método sistémico es el método con mayor importancia en la interpretación constitucional, pues engloba tres aspectos: coherencia, que la interpretación no debe colisionar con las demás normas pues deben guardar la compatibilidad; lugar de ubicación, que en caso de existir una norma dudosa, se debe tener en cuanto al momento de interpretarla, el lugar que ocupa dentro del texto constitucional del que forma parte y; criterio sistémico en sentido estricto, que al momento de atribuirle un significado se debe tener en cuenta el contexto, es decir, los otros preceptos o normas que lo rodean.

El método histórico, consiste en analizar los antecedentes de las normas con la finalidad de encontrar su sentido en la actualidad. En el caso de la Constitución, se trata de los precedentes constitucionales y los debates parlamentarios que dieron origen a su aprobación. Cabe agregar que el propio Tribunal Constitucional reconoce la importancia de este método y lo ha venido aplicando, tal como se desprende del siguiente texto:

${ }^{6}$ Ibíd. P. 417-418. 
“(...) 14. Es evidente, a la luz de la historia del derecho constitucional peruano, que las Constituciones de 1920, 1933 y 1979 establecieron, como parte del proceso de ratificación judicial, la obligatoriedad de la motivación de la resolución correspondiente. Sin embargo, no ha sido esta una exigencia que se haya incorporado al texto de 1993. Por el contrario, de manera indubitable y exprofeso, los legisladores constituyentes de dicha Carta optaron por constitucionalizar la no motivación de las ratificaciones judiciales, diferenciando esta institución de lo que, en puridad, es la destitución por medidas disciplinarias (cf. Congreso Constituyente Democrático. Debate Constitucional-1993, T.III,p. 1620 yss.).

Desde una interpretación histórica es claro que el mecanismo de ratificación judicial ha cambiado y, por ende, actualmente es percibido como un voto de confianza o de no confianza respecto a la manera como se ejerce la función jurisdiccional y, como tal, la decisión que se tome en el ejercicio de dicha competencia no requiere ser motivada; a diferencia de la destitución que, por su naturaleza sancionatoria, necesaria e irreversiblemente debe ser explicada en sus particulares circunstancias. "7"

No obstante que el método histórico es uno de los idóneos para la interpretación constitucional, es fundamental tener en cuenta que éste debe ser utilizado luego de someterse a la crítica de la realidad social del momento en que se aplica el Derecho, pues sólo será de utilidad si las condiciones históricas no han variado; por tanto, si la realidad conduce a una interpretación diferente que la del momento de aprobación de las normas y a sus antecedentes, se debería dejar de lado el método histórico y optar por otro.

El método sociológico propone que la interpretación sea acorde con la sociedad que regula, pues la finalidad de las normas es dirigir la conducta de las personas dentro de dicha sociedad al momento que estas entablen relaciones recíprocas. Cabe mencionar, este método es útil en la medida que constantemente proporciona a los derechos constitucionales vigencia normativa.

Finalmente, el método de ratio legis o intención de la ley no es otra cosa que darle a la norma un alcance interpretativo según su razón de ser, esto es, según su finalidad. Este método influye 0 condiciona a casi todos los demás métodos, en la medida que hace prevalecer a los fines esenciales de la Constitución.

Ahora bien, tal como se ha mencionado, aún cuando se reconozca la utilidad de los criterios referidos, éstos por si mismos no permiten realizar la labor de interpretación de todos los preceptos constitucionales, por lo que si bien son necesarios no son suficientes. Y, en este orden de ideas, han surgido métodos específicos para la interpretación constitucional, los cuales ponen sobre el tapete la especificidad de la Norma Constitucional, lo que debe estar presente al momento de interpretarla. Sobre el particular, Díaz Revorio ${ }^{8}$ considera, entre los criterios o elementos específicos de la interpretación constitucional, lo siguiente:

“(...) En primer lugar puede apuntarse el principio de unidad de la Constitución, que supone, como ya hemos apuntado, considerar a ésta como un todo que se sitúa en la cúspide del ordenamiento y debe presidir, a su vez, la interpretación de este. En segundo lugar, el principio de concordancia práctica, según el cual los conflictos posibles entre preceptos constitucionales no deben resolverse en base a la supuesta superioridad de alguno de ellos y el sacrifico de otros, sino mediante la ponderación, en cada caso concreto, que permita una cierta realización de los principios en tensión. En tercer lugar, hay que destacar el principio de fuerza normativa de la Constitución, que presupone el carácter jurídico y vinculante de cada uno de sus preceptos. En cuarto lugar, el principio de corrección funcional, que implica el respeto a la distribución de poderes y funciones que deriva de la

\footnotetext{
${ }^{7}$ Sentencia del Tribunal Constitucional emitida el 08 de abril de 2003. Expediente No 0578- 2003-AA-TC sobre Acción de Amparo seguida por Julia Eleyza Arellano contra el CNM y sus integrantes.

${ }^{8}$ Óp. Cit. P.251-252.
} 


\section{propia Constitución.}

De este modo, la suma de los criterios tradicionales y de los especificos de la Constitución (literal, sistemático, histórico, teleológico, interpretación evolutiva, concordancia práctica, unidad de la Constitución, corrección funcional, carácter abierto de sus preceptos...) Ilevará a la utilización conjunta de todos o algunos de ellos, según los casos, y permitirá resolver la mayoría de los problemas interpretativos, siempre teniendo en cuenta que, el primer sujeto legitimado para interpretar y desarrollarla constitución es el legislador".

Del texto citado, se puede colegir que, luego de establecido o determinado el método(s) de interpretación constitucional, nos encontramos con la segunda cuestión controversia: quien (es) son los legitimados para interpretar la Constitución?.

\section{EL TRIBUNAL CONSTITUCIONAL COMO INTÉRPRETE DE LA CONSTITUCIÓN}

Entre los sujetos que pueden interpretar la Constitución, el Tribunal Constitucional es el órgano jurisdiccional superior que, como órgano técnico, se encarga de interpretar o dotar de contenido a los valores constitucionales.

Antes de realizar un análisis sobre la labor del Tribunal Constitucional y los extremos de su funcionalidad, es importante mencionar al legislador como el otro intérprete de la Norma Fundamental, quien recibe el nombre de intérprete primario.

El legislador viene a ser el intérprete primario de la Constitución, pues aún cuando su función principal no es la interpretación, sino mas bien, la creación y/o aprobación de normas jurídicas en representación de la voluntad popular, éste termina interpretando las normas constitucionales al momento de la producción de las normas legales. En otras palabras, el legislador cuando dá soluciones a distintas situaciones o problemas de la sociedad, se encuentra efectuando una previa interpretación de la Constitución, pues debe respetar los límites impuestos por ella.

A esta forma de interpretar del Poder Legislativo también se le denomina "interpretación auténtica". La interpretación auténtica es definida "como el proceso por el cual el órgano competente que dictó previamente una norma, aclara su sentido posteriormente, en el sentido que la primera norma se entiende de la manera en que lo establece la segunda, desde su aprobación inicial". ${ }^{9}$

Marcial Rubio define a la interpretación auténtica como "aquella que realiza sobre la misma norma y siguiendo el mismo procedimiento que se adoptó para producirlo, la autoridad que tiene la competencia de dictarla o derogarla. Así, hay interpretación auténtica cuando el Congreso, mediante ley, interpreta una ley anterior o cuando el poder ejecutivo, mediante decreto supremo, interpreta un decreto supremo previo, y así sucesivamente". Además, agrega que "quien interpreta auténticamente, aclara el sentido de una norma dictada antes, con la autoridad suficiente como para que, desde siempre, se entienda que el sentido de la norma original era el que le da la interpretación posterior. En otras palabras, la interpretación auténtica da sentido a la norma ya existente, no desde que la interpretación es aprobada, sino, desde que la norma interpretada entró en vigencia. La interpretación auténtica, en el derecho, es, así, irrebatible". ${ }^{10}$

Ahora bien, el Tribunal Constitucional, en contrapartida con el legislador, vendría a ser el legislador secundario. Ello, en tanto que la interpretación sólo se produce en caso de conflictos constitucionales y, a instancia de una parte legitimada. Es decir, el Tribunal Constitucional realiza una interpretación cuando, previamente, la norma constitucional ya ha sido sujeta a una interpretación por parte del legislador 0 , en todo caso, de los órganos jurisdiccionales.

\footnotetext{
${ }^{9}$ BERNALES BALLESTEROS, Enrique. En: El Peruano - Edición del 06/04/2005 - Pagina 32. http://www.abogadoperu.com/peruano-fecha20050406-pagina-32.php

${ }^{10}$ RUBIO CORREA, Marcial. Interpretando auténticamente a la mayoría. En: http://w3.desco.org.pe/publicaciones/QH/QH/mr102.htm
} 
La existencia de diferentes intérpretes de la Constitución ha originado, en el pasado, cierta tensión entre ellos. En el Perú, dicha tensión se concretizó cuando el 23 de agosto de 1996 se promulgó la Ley No 26657 o Ley de Interpretación Auténtica del artículo $112^{\circ}$ de la Constitución de 1993, mediante la cual se permitía la reelección del ex Presidente Alberto Fujimori. Ante la promulgación de dicha norma, el Colegio de Abogados de Lima presentó una acción de inconstitucionalidad ante el Tribunal Constitucional $y$, éste falló declarando la inaplicabilidad de la norma constitucional al caso concreto del ex presidente Fujimori, lo cual conllevó a un cuestionamiento político contra los magistrados que votaron a su favor (Dr. Aguirre Roca, Dr. Rey Terry y Dra. Revoredo Marsano).

Tanto así, que el grupo parlamentario que apoyó la promulgación de la Ley de Interpretación Auténtica presentó una denuncia constitucional contra los referidos magistrados del Tribunal Constitucional ante el Congreso de la República, ocasionando la destitución de los mismos el 28 de mayo de 1997, mediante resoluciones legislativas No 002-97-CR, 003-97-CR y 004-97-CR.

Este contexto de enfrentamiento o tensión materializada entre los dos intérpretes de la Constitución, el Congreso de la República (intérprete primario) y el Tribunal Constitucional (intérprete secundario), concluyó cuando el Pleno del nuevo Congreso elegido en el año 2000 y presidido por el Dr. Valentín Paniagua decidió abdicar de su posición y aprobó la restitución de los tres magistrados del Tribunal Constitucional en el año 2000.

Por consiguiente, no fue el "poder" o "supremacía" del Tribunal Constitucional que, en este momento histórico, se impuso frente al órgano legislativo, sino, más bien, fue una decisión adoptada por uno de los involucrados en aras de reconstruir la inestabilidad jurídica - constitucional.
En principio, el carácter legal de "supremo intérprete" dota al Tribunal Constitucional de un excesivo poder, pues su interpretación prevalecerá sobre la realizada por cualquier otro órgano o poder del Estado. Es decir, prevalecerá sobre la interpretación efectuada por el Gobierno y la Administración Pública, pudiendo declarar inconstitucionales sus resoluciones y disposiciones; sobre la realizada por los órganos integrantes del Poder Judicial, cuyas decisiones pueden ser revisadas por el Tribunal Constitucional y; sobre la realizada por el legislador, pues el Tribunal Constitucional puede incluso expulsar del ordenamiento normas con rango de ley si éstas atentan con los valores y principios contenidos en la Norma Fundamental.

No obstante, dicho poder no es ilimitado, en la medida que la actuación del Tribunal Constitucional se encuentra supeditado en primer lugar, al Poder Constituyente 0 al "Poder Constituyente Constituido", pues éste puede modificar la Constitución alterando su configuración y funciones o, incluso, podría suprimirlo; en segundo lugar, al Poder Legislativo, en tanto que éste tiene facultades para aprobar o modificar su ley orgánica; en tercer lugar, a los tribunales internacionales.

Al respecto, la fijación de límites que ejerce el Tribunal Constitucional como parte de dicho control constitucional, es un debate permanente no sólo por parte de los académicos sino de toda la comunidad, existiendo incluso intenciones de recorte de facultades a partir de una propuesta legislativa; la misma, que fundamentan que el Tribunal Constitucional habría usurpado facultades legislativas propias del Congreso.

Antes de profundizar sobre este último tema, esto es, la "conversión" del Tribunal Constitucional en creador de normas, resulta necesario mencionar los diversos tipos de sentencias que el Tribunal Constitucional emite al momento de ejercer su función de máximo intérprete de la Constitución: 


\subsection{Sentencias Interpretativas}

Marcial Rubio" sostiene, que las sentencias interpretativas se refieren al contenido normativo de las disposiciones de rango de ley que puedan tener más de una interpretación posible. De estas varias interpretaciones, una debe ser acorde con la Constitución y la otra - o las otras - no lo serán. Entonces, el Tribunal Constitucional, en la sentencia interpretativa, escoge la interpretación constitucionalmente correcta como válida y la aplica, señalando que elegir las interpretaciones alternativas conducirán a la declaración de inconstitucionalidad, desde luego, en la aplicación de la norma.

Como es obvio, esa declaración de inconstitucionalidad se hará a través del control difuso 0 caso por caso, pues el texto dispositivo en realidad no es inconstitucional. Esto último no lo ha dicho expresamente el Tribunal, pero se desprende del sentido del principio que aplica.

Lo que sí ha dicho el propio Tribunal Constitucional es que la finalidad de las sentencias interpretativas es evitar vacíos y lagunas. Ello, en la medida que cuando se declara inconstitucional una norma de rango de ley, ésta es invalidada y se produce una extinción normativa; pues podría ser que esa norma no sólo contuviera la inconstitucionalidad que la ha llevado a ser declarada así, sino que hubiera sido emitida para ordenar una regulación normativa. En esa medida, al ser declarada inconstitucional, el orden que pretendía imponer ya no existe y, por tanto, se produce una anormalidad legislativa.

Un ejemplo de sentencia interpretativa puede ser, que un decreto supremo estableciera normas tributarias que pertenecen a la reserva de ley $y$ sustituyera la alícuota existente por una nueva. El Tribunal hace control difuso de ese decreto supremo en un proceso de amparo, pero no da interpretación alternativa alguna. El efecto es que el contribuyente queda desgravado, porque no hay forma de aplicarle el tributo: la nueva tasa es inconstitucional y la anterior fue derogada, aunque impropiamente (...) Por consiguiente, en un caso como éste, el Tribunal no sólo hará control difuso sino que, en aplicación de sus responsabilidades, deberá también decir si mantienen o no la tasa antigüa o de que otra manera se aplica el tributo para no crear una desgravación tan particular. Esto sería precisamente, una sentencia interpretativa. ${ }^{12}$

Asimismo, las sentencias interpretativas, a su vez, pueden ser sentencias estimatorias 0 desestimatorias y/o sentencias extensivas 0 restrictivas. Son sentencias estimatorias las que declaran fundada la demanda y desestimatorias las que las declaran infundada. Son sentencias extensivas las que se orientan a alcanzar mayores niveles de protección y son sentencias restrictivas las que determinan que el ámbito de aplicación de la norma quede reducido.

\subsection{Sentencias aditivas}

Al respecto, el Tribunal Constitucional señala: "Por el contrario, mediante las sentencias denominadas aditivas, se declara la inconstitucionalidad de una disposición o una parte de ella, en cuanto se deja de mencionar (<en la parte que no prevé que>) que era necesario que se previera para que ella resulte conforme a la Constitución. En tal caso, no se declara la inconstitucionalidad de todo el precepto legal, sinó sólo de la omisión, de manera que, tras la declaración de inconstitucionalidad, será obligatorio comprender dentro de la disposición aquello omitido." 13

En otras palabras, la sentencia aditiva declara la inconstitucionalidad de una norma que fue omitida dentro de un dispositivo legal y, el Tribunal corrige dicha norma que hacía falta para darle solución al problema, de manera tal que la norma que se omitió será añadida y aplicada en el futuro. Adicionalmente, es importante resaltar que la sentencia aditiva no crea normas, sino que corrige

\footnotetext{
${ }^{11}$ RUBIO CORREA, Marcial. Óp. Cit. P. 400.

${ }^{12}$ Ibíd. P. 402.

${ }^{13}$ Sentencia del Tribunal Constitucional emitida el 03 de enero de 2003. Expediente No 0010- 2002-Al-TC sobre Acción de Inconstitucionalidad seguida contra los decretos leyes 25475,25659 y 25880 , sus normas complementarias y conexas.
} 
constitucionalmente una norma de rango inferior y, para que sea válida dicha sentencia ésta debe deducirse en forma clara del texto y de los principios constitucionales. Sobre el particular, el Tribunal ha manifestado:

"Los <silencios> constitucionales no pueden ser interpretados como tácitas concesiones al legislador, a efectos de que expida regulaciones desvinculadas de la Norma Fundamental. Allí donde las <normas regla> previstas en la Constitución omiten precisiones, la ley 0 , en su caso, el Reglamento parlamentario están obligados a estipularlas, pero siempre en vinculación directa a las <normas principio> contenidas en la propia Norma Fundamental." ${ }^{14}$

\subsection{Sentencias sustitutivas}

Como su nombre lo dice, las sentencias sustitutivas sustituyen en un dispositivo legal una parte declarada inconstitucional por otra que es considerada por el Tribunal como constitucional, enmendando el problema. De esta manera, el dispositivo es corregido y reconstruido al momento de ser aplicado.

Una de las sentencias sustitutivas emblemáticas es la que se cita:

"Que, el término sevicia utilizado en el artículo 3370 del Código Civil y también por los demandados en la contestación a la demanda, debe entenderse sustituido por el de <violencia física y psicológica> y no solo referido, como parece ser la parte demandada, a los actos de crueldad física; que la violencia física y psicológica a la que se refiere el artículo impugnado del Código Civil, es una violencia alegada como fundamento por la presunta víctima para solicitar la separación de cuerpos o el divorcio, por lo que no cabe presumir que ha consentido con ella, o que la ha perdonado, sino mas bien, que no está dispuesto a tolerarla ni por costumbre ni por miedo a la separación o al divorcio, ni por su grado de educación o cultura; que la existencia de violencia debe ser comprobada por el juez respecto a su debida existencia de modo objetivo que, planteada la demanda de separación de cuerpos o divorcio por el cónyuge agredido, y comprobada la existencia de violencia por acto o por conducta del otro cónyuge queda configurada y tipificada la circunstancia a que se refieren los artículos $333^{\circ}$ y $349^{\circ}$ del Código Civil como causal de separación de cuerpos y de divorcio vincular, pues la violencia no deja de ser tal por el hecho de quien la realiza o el que la sufre, o ambos, tengan determinado nivel de educación o cultura o, vivan en un ambiente donde se acostumbra aceptarla, pues en todos los casos vulnera la integridad física y psíquica de la víctima, así como su dignidad y derecho a vivir en paz; que, en consecuencia, siempre que haya indicios de violencia física 0 psicológica por uno de los cónyuges, debe bastar la exigencia de la presunta víctima a la separación de cuerpos o al divorcio para que sea admitida como presunta causal y pueda iniciarse el proceso; que, dentro del proceso, una vez comprobada fácticamente la violencia, queda probada también la vulneración a los principios constitucionales precitados, y no cabe, por ende, supeditar su carácter de causal, a la educación o conductas de los cónyuges." 15

\subsection{Sentencias exhortativas:}

El Tribunal Constitucional cuando emite una sentencia exhortativa está indicando que existe una inconstitucionalidad y avisando al órgano competente para que modifique la norma dentro de un plazo razonable. Sin embargo, la exhortación no se encuentra liberada de consecuencias, pues si aun no se hizo la modificación y existiera un proceso que versara sobre el tema ante el Tribunal, lo correcto y coherente seria que este ejerza el control difuso sobre la materia de dicho proceso.

Como ejemplo de una sentencia exhortativa citamos la recaída en el proceso seguido sobre

\footnotetext{
${ }^{14}$ Sentencia del Tribunal Constitucional emitida el 01 de diciembre de 2003. Expediente No 0006-2003-Al-TC sobre Acción de Inconstitucionalidad seguida contra el inciso f) del artículo 89 del Reglamento del Congreso de la república.

${ }^{15}$ Sentencia del Tribunal Constitucional emitida el 29 de abril de 1997. Expediente No 0018- 1996-I-TC sobre Acción de Inconstitucionalidad seguida contra artículo 337o del Código Civil.
} 
acción de inconstitucionalidad contra el inciso f) del artículo 890 del Reglamento del Congreso de la República, de fecha 01 de diciembre de 2003, Expediente No 0006-2003-Al-TC:

"El Tribunal Constitucional exhorta al Congreso de la República a legislar un procedimiento y la necesidad de una votación calificada para poder declarar la vacancia presidencial por la causal prevista en el inciso 2) del artículo $113^{\circ}$ de la Constitución, a efectos de no poder incurrir en aplicaciones irrazonables de la referida disposición constitucional, para lo cual, al igual que en los casos de juicio político, debe estipularse una votación calificada no menor a los 2/3 del numero legal de miembros del Congreso".

\subsection{Sentencias estipulativas}

Una sentencia estipulativa es aquella que define conceptos, declarándolos con el fin de que queden claros y preestablecidos. Por ello, se dice que el Tribunal, a través de estas sentencias, contribuye a definir instituciones, conceptos y principios, eligiendo una entre varias opciones.

El Tribunal Constitucional en la Sentencia de fecha 06 de febrero de 2005 dictada entre el Expediente Nº004-2004-CC7TC señaló:

"Las sentencias estipularias son aquellas en donde el órgano de control de la constitucionalidad establece, en la parte considerativa de la sentencia, las variables conceptuales o terminológicas que utilizará para analizar y resolver una controversia constitucional". ${ }^{16}$

\subsection{Sentencias manipulativas}

Finalmente, se denomina sentencia manipulativa a aquella que se emite cuando el órgano de control constitucional se percata de la existencia de un contenido normativo inconstitucional dentro de una ley impugnada, por lo que la sentencia contiene dos tipos de operaciones: la ablativa o reductora y, la reconstructiva 0 aditiva.

En ese sentido, la sentencia ablativa o reductora consiste en reducir los alcances normativos de la ley, tal como el propio Tribunal Constitucional lo ha sostenido:

“(...) La sentencia reductora restringe el ámbito de aplicación de la ley impugnada a algunos de los supuestos o consecuencias jurídicas establecidas en la literalidad del texto"."

$Y$, por su parte, la sentencia reconstructiva 0 aditiva consiste en ampliar el alcance normativo de la ley agregándosele un contenido y sentido de interpretación que no aparece en el texto por sí mismo. Sobre el mismo, el Tribunal ha mencionado:

“(...) La sentencia aditiva se presenta cuando el Tribunal advierte que una parte de la ley impugnada es inconstitucional, en tanto que no ha previsto 0 ha excluído algo, por lo que procede a <ampliar> 0 <extender> su contenido normativo, permitiendo su aplicación a supuestos inicialmente no contemplados, o ensanchando sus consecuencias jurídicas. Su finalidad consiste en controlar 0 integrar las omisiones legislativas constitucionales. El contenido de los <adicionado> surge de la interpretación extensiva, de la interpretación sistémica o de la interpretación analógica".

Las sentencias manipulativas tienen su razón de ser en la medida que buscan evitar los efectos negativos que puedan presentarse como consecuencia de los vacíos legales que surgen luego de la expulsión de una ley del ordenamiento; por lo que tienen como sustento dos principios rectores: el principio de la conservación de la ley y el principio de la interpretación desde la Constitución; así como tienen los siguientes limites:

“(...) a) el principio de separación de poderes; b) no cabe dictarlas cuando exista más de una manera de

\footnotetext{
${ }^{16}$ Sentencia del Tribunal Constitucional emitida el 06 de febrero de 2005. Expediente №0004-2004-CC/TC sobre Acción de Inconstitucionalidad.

${ }^{17}$ Sentencia del Tribunal Constitucional emitida el 06 de febrero de 2005. Expediente $N^{\circ} 0004-2004-C C / T C$ sobre Acción de Inconstitucionalidad.

${ }_{18}^{18}$ Sentencia del Tribunal Constitucional emitida el 06 de febrero de 2005. Expediente $N^{\circ}$ 0004- 2004-CC7TC sobre Acción de Inconstitucionalidad.
} 
cubrir el vacío normativo que la declaración de inconstitucionalidad pueda generar; c) solo pueden emitirse cuando según imprescindibles a efectos de evitar que la simple declaración de inconstitucionalidad residente en la ley impugnada, genere una inconstitucionalidad de mayores alcances y perversas consecuencias para el Estado social y democrático de derecho; d) solo resultan legítimas en la medida de que se argumenten debidamente las razones y los fundamentos normativos constitucionales que, a luz de lo expuesto, justifiquen su dictado; y, e) la emisión de estas sentencias requiere de la mayoría calificada de votos de los miembros del Tribunal Constitucional".

\section{EL TRIBUNAL CONSTITUCIONAL COMO LEGISLADOR POSITIVO}

Ahora bien , la cuestión en controversia radica en la facultad del Tribunal Constitucional de expedir sentencias interpretativas, precedentes vinculantes y de crear doctrina jurisprudencial, pues ellas implican - para un sector de la doctrina el ejercicio real de facultades legislativas (legislador positivo), pues nos dicen que:

" (...) Ciertamente, nadie duda que el Tribunal Constitucional es un "legislador positivo". Es consenso aceptar (y ha sido reconocido por la Constitución) que este Tribunal tiene la facultad de expulsar del ordenamiento jurídico las normas con rango de ley contrarias a la Constitución Política vía proceso de inconstitucionalidad. El problema viene con las supuestas facultades de "legislador positivo" antes mencionadas, en la medida que ellas vendrían a incorporarse al sistema de fuentes del derecho. ${ }^{19}$

Sobre el particular, se precisa específicamente que la emisión de precedentes vinculantes y el desarrollo de jurisprudencia constitucional mediante sentencias interpretativas, violaría el principio de separación de poderes; por cuanto, el Tribunal Constitucional se estaría atribuyendo facultades de manera extra constitucional, para actuar como legislador positivo, excediendo con ello sus atribuciones.

El mismo Tribunal Constitucional, ha precisado como para de su misión, el señalar limites al ejercicio del poder por los órganos e instituciones del Estado, justificando su existencia en la necesidad de velar por una correcta aplicación de la Norma Constitucional y su prevalencia frente a cualquier otra, justificando en dicha tarea su facultad interpretativa. Sobre ello señaló, que:

“(...)el Tribunal Constitucional tiene como tareas la racionalización del ejercicio del poder, el cual se expresa en los actos de los operadores del Estado, el mismo que debe encontrarse conforme con las asignaciones competenciales establecidas por la Constitución; asimismo, vela por la preeminencia del texto fundamental de la República sobre el resto de las normas del ordenamiento jurídico del Estado; igualmente se encarga de velar por el respeto y la protección de los derechos fundamentales de la persona, así como de ejercer la tarea de intérprete supremo de los alcances y contenidos de la Constitución" ${ }^{20}$

Del mismo modo, ha llegado a justificar dicha labor interpretativa a partir de su función como órgano de control constitucional asignada por la Constitución, señalando lo siguiente:

"(...)el Tribunal Constitucional, en su condición de órgano de control de la Constitución (artículo $201^{\circ}$ de la Constitución) y órgano supremo de interpretación y control de la constitucionalidad (artículo 10 de la Ley No 28301), tiene en el proceso de inconstitucionalidad, funciones esenciales tales como: a) la valoración de la disposición sometida a enjuiciamiento a partir del canon constitucional, para declarar su acomodamiento o nó a ese canon; b) la labor de pacificación, pues debe solucionar controversias mediante decisiones cuyos efectos deben ser modulados de acuerdo a cada caso; y, c) la labor de ordenación, toda vez que, sus decisiones, ya sean estimatorias o desestimatorias,

\footnotetext{
${ }^{19}$ RUIZ MOLLEDA, Juan Carlos. .Es el Tribunal Constitucional un Legislador Positivo? Consorcio Justicia Viva.

http//www.justiciaviva.org.pe/justiciamail/jm0299.htm.

${ }^{20}$ Fundamento 1 de la STC 2409-2002-AA/TC emitida por el Tribunal Constitucional el 07 de noviembre de 2002.
} 
tienen una eficacia de ordenación general con efecto vinculante sobre los aplicadores del Derecho -en especial sobre los órganos jurisdiccionales-, y sobre los ciudadanos en general(...)".

\section{FUNDAMENTOS DESARROLLADOS POR EL TRIBUNAL CONSTITUCIONAL PARA JUSTIFICAR SU ACTUACIÓN COMO LEGISLADOR POSITIVO}

El Tribunal a lo largo de diversa jurisprudencia constitucional, se ha encargado de precisar y delimitar sus funciones, justificando su capacidad de emitir precedentes vinculantes y dictando sentencias interpretativas, implicando en ellas el ejercicio material de facultades legislativas (legislador positivo). Entre dichos fundamentos encontramos:

\subsection{La necesidad de evitar efectos perniciosos}

Una de las primeras justificaciones, ha resultado de las consecuencias habituales frente a la declaratoria de inconstitucionalidad de las normas, siendo que ellas pueden generar vacíos y desordenes que son imprescindibles afrontar y evitar, estando en la voluntad del Tribunal, modular la aplicación de lo resuelto evitando con ello efectos perniciosos a la sociedad, que implicaría afectación de derechos fundamentales. Así, pues, los efectos de dicha declaración pueden producir, durante un "tiempo", un vacío legislativo dañoso para la vida coexistencia.

Al respecto, en la sentencia dictada por ocasión del conflicto de competencia entre el Poder Judicial y el Congreso de la República, el Tribunal Constitucional ha dejado zanjado su posición al respecto, justificando dicha situación en la existencia de los principios de conservación de la ley y el principio de interpretación desde la Constitución.

Sobre ello, se pronunció que: "La existencia de este tipo de sentencias se justifica por la necesidad de evitar los efectos perniciosos que puedan presentarse en determinadas circunstancias, como consecuencia de los vacíos legales que surgen luego de la "expulsión" de una ley o norma con rango de ley del ordenamiento jurídico. Tales circunstancias tienen que ver con la existencia de dos principios rectores de la actividad jurisdiccional-constituyente, a saber: el principio de conservación de la ley y el principio de interpretación desde la Constitución (...)". ${ }^{22}$

Sobre el principio de conservación de la ley, éste busca propender en lo posible, una solución acorde, vía interpretación con el ordenamiento legal, evitando de tal manera la generación de vacíos normativos al eliminarse las normas de naturaleza inconstitucional; buscando en definitiva "salvar", hasta donde sea razonablemente posible, la constitucionalidad de una ley impugnada, en aras de afirmar la seguridad jurídica y la gobernabilidad del Estado.

Debemos señalar, que para el Tribunal Constitucional, la expulsión de la ley (función de legislador negativo) en estricto, deber ser la última ratio a la que debe recurrir, por lo que la función precisada en el artículo $204^{\circ}$ de la Constitución, de dejar sin efecto una norma, debe ser interpretada como una facultad que debe ser utilizada, sólo si es imprescindible e inevitable. Del mismo modo, el principio de interpretación desde la constitución, busca asignar un sentido a la norma cuestionada de inconstitucionalidad, a efectos de que guarde coherencia y armonía con la Constitución. De esta forma, se busca que la norma sea conforme a la Constitución, pudiendo para ello utilizar diversas formas resolutorias propendiendo su reducción, sustitución o modificación en su aplicación.

En ese sentido, lo que busca el Tribunal Constitucional es desarrollar una función que armonice los conflictos jurídicos o políticos que emanan de un proceso constitucional, por lo que la generación de sentencias modulando sus efectos -para evitar la expulsión de la norma del ordenamiento- , es uno de los instrumentos más usados.

\footnotetext{
${ }^{21}$ Fundamento 16 de la STC 0054-2004-AI/TC emitida por el Tribunal Constitucional el 13 de abril de 2005.

${ }^{22}$ Fundamento 3.3 de la STC 004-2004-CC/TC emitida por el Tribunal Constitucional el 31 de diciembre de 2004.
} 
5.2. Efectos de los pronunciamientos del Tribunal Constitucional

Sobre ello, debemos señalar, que el Tribunal Constitucional, en base a su calidad de máximo órgano de control constitucional, ha precisado que sus decisiones no pueden ser desconocidas por los operadores del derecho, siendo que ésta ha sido la voluntad del constituyente.

Sobre ello, se ha precisado que:

"Así, respecto a la sentencia 009-2001-Al/TC, es de provecho resaltar que si la Constitución reconoce al Tribunal Constitucional como el órgano de control de la Constitución y de la constitucionalidad de las leyes (artículo $201^{\circ}$ ) y le ha reservado la posición de ser, en algunos procesos constitucionales, instancia final de fallo y, en otros, instancia única (articulo 202 ${ }^{\circ}$ ), entonces sus sentencias no pueden ser desconocidas por los demás poderes $u$ órganos constitucionales del Estado e, incluso, por los particulares" ${ }^{23}$

En ese sentido, dicha interpretación justifica la cobertura que mantendría la jurisprudencia constitucional hacia todo el sistema jurídico; por cuanto, muchas veces las normas 0 actos impugnados mediante procesos constitucionales no sólo afectan a quienes las plantean y al resultar dichos hechos contrarios a la Constitución contienen efectos generales.

\subsection{Principio de la autonomía procesal}

Mediante el Principio de Autonomía Procesal, el Tribunal Constitucional tiene la potestad de modular, procesalmente, el contenido y los efectos de sus sentencias en todos los procesos constitucionales, en general y en el proceso de amparo, en particular.

Dicho principio se desprende tanto de la propia naturaleza del Tribunal como de lo señalado por el artículo $201^{\circ}$ de la Constitución, según la cual, el
Tribunal Constitucional mantiene autonomía para configurar, a través de sus sentencias, los procesos constitucionales que son de su competencia.

Al respecto, se ha manifestado, indicando que:

"Según el principio de autonomía procesal, el Tribunal Constitucional detenta en la resolución de cada caso concreto la potestad de establecer, a través de su jurisprudencia, normas que regulen el proceso constitucional, a través del precedente vinculante del artículo VII del Código Procesal Constitucional, en aquellos aspectos donde la regulación procesal constitucional presenta vacíos normativos o donde ella debe ser perfeccionada o adecuada a los fines del proceso constitucional." ${ }^{24}$

Si bien, dicho principio ha sido la justificación para modular y emitir en forma creativa según el caso concreto, resoluciones que otorguen solución al problema constitucional controvertido, el mismo Tribunal Constitucional como forma de auto limitarse a señalado ciertas reglas, como son:

"La autonomía procesal está sujeta a los siguientes limites:

a) La regulación constitucional y legal en donde se han establecido los principios fundamentales del proceso constitucional, en este caso el artículo $200^{\circ}$ de la Constitución, el Código Procesal Constitucional y la Ley Orgánica del Tribunal Constitucional.

b) Se realiza en base al uso del Derecho Constitucional material, pero no de manera absoluta.

c) Debe reconocer el lugar que ocupa el Derecho Procesal Constitucional dentro del ámbito del Derecho Procesal general, afirmándose la naturaleza del Tribunal Constitucional como órgano jurisdiccional, sin que ello suponga negar las singularidades de la jurisdicción constitucional y los principios materiales que la informan". ${ }^{25}$

\footnotetext{
${ }^{23}$ Fundamento 36 de la STC 006-2006-CC emitida por el Tribunal Constitucional el 13 de febrero de 2007.

${ }^{24}$ Fundamentos 18-21 de la STC 0025-2005-Al/TC y 0026-2005-Al/TC (acumulados) emitida por el Tribunal Constitucional el 28 de octubre de 2005.

${ }^{25}$ Fundamento 3 de la STC 0020-2005-AI/TC y 0021-2005-AI/TC (acumulados) emitida por el Tribunal Constitucional el 08 de agosto de 2005.
} 
En ese sentido, debemos indicar que es el Tribunal Constitucional el titular de dicho principio de autonomía procesal, que le otorga la facultad de desarrollar y complementar la regulación procesal constitucional a través de la jurisprudencia que emana, sacrificando incluso las formas procesales con el fin de tutelar derechos constitucionales.

Esta capacidad para delimitar el ámbito de sus decisiones por parte del Tribunal, tiene como presupuesto la necesidad de dotar de todo el poder necesario en manos del Tribunal para tutelar los derechos fundamentales más allá, incluso de las intervenciones de las partes, pero sin olvidar que la finalidad no es para el atropello o la restricción.

Este "sacrificio de las formas procesales" sólo puede encontrar respaldo en una única razón, la tutela de los derechos, por lo que toda práctica procesal que se apoye en este andamiaje teórico para atropellar los derechos o para disminuir su cobertura, debe ser rechazado como un poder peligroso en manos de los jueces.

\subsection{Tutela Jurisdiccional Efectiva}

Otro fundamento de la capacidad de legislar del Tribunal Constitucional, ha sido el ejercicio por éste del derecho a la tutela judicial efectiva, el cual a su vez contiene el derecho a obtener una resolución fundada en derecho, es decir, que la fundamentación en derecho se atenga al sistema de fuentes establecido, del cual forma parte la jurisprudencia del Tribunal Constitucional.

Sobre ello, el Tribunal Constitucional ha precisado, que:

"Este Tribunal Constitucional ha señalado que el derecho a la debida motivación de las resoluciones como parte del debido proceso, implica que una resolución deba contar con suficiente motivación tanto de los hechos como de la interpretación y/o razonamiento de normas invocadas. Por otro lado, la motivación de una decisión no sólo consiste en expresar la norma legal en la que se ampara, sinó fundamentalmente, en exponer suficientemente las razones de hecho y el sustento jurídico que justifican la decisión tomada". ${ }^{26}$

En ese sentido, dicha fundamentación es inherente a la idea de sentencia, debiendo comportar que dicha resolución dictada por el órgano jurisdiccional se base en la norma adecuada al caso, no debiendo contener elementos de naturaleza arbitrarios ni irracionales, debiendo en inconstitucional si fuera así. Es por ello, que desconocer o no tomar en cuenta la jurisprudencia constitucional como una fuente del derecho que es emanada en defensa de los derechos constitucionales, viola en sí la tutela jurisdiccional efectiva.

\section{RESPECTO A LOS PRECEDENTES VINCULANTES}

Los precedentes vinculantes emitidos por el Tribunal Constitucional, son herramientas procesales que ayudan a la ordenación y coherencia en el desarrollo de la jurisprudencia constitucional. El Tribunal Constitucional, ha basado su utilización en lo preceptuado por el Código Procesal Constitucional, que señala:

\section{"Articulo VII.-Precedente}

Las sentencias del Tribunal Constitucional que adquieren la autoridad de cosa juzgada, constituyen precedente vinculante cuando asi lo exprese la sentencia, precisando el extremo de su efecto normativo. Cuando el Tribunal Constitucional resuelva apartándose del precedente, debe expresar los fundamentos de hecho y de derecho que sustentan la sentencia y las razones por las cuales se aparta del precedente". ${ }^{27}$

En sí, debemos indicar que la naturaleza del precedente vinculante mantiene una doble connotación. Por un lado, aparece como una herramienta técnica que facilita la ordenación y coherencia de la jurisprudencia; y, por otro, expone el poder normativo del Tribunal Constitu-

\footnotetext{
${ }^{26}$ Fundamento 3 de la STC 03283-2007-PA/TC emitida por el Tribunal Constitucional el 3 de septiembre de 2007.

${ }^{27}$ Artículo VII del Título Preliminar del Código Procesal Constitucional.
} 
cional dentro del marco de la Constitución, el Código Procesal Constitucional y la Ley Orgánica del Tribunal Constitucional.

Adecir del Tribunal Constitucional:

"El precedente constitucional vinculante es la regla jurídica expuesta en un caso concreto que el Tribunal decide establecer como regla general; $y$, que, por ende, deviene en parámetro normativo para la resolución de futuros procesos de naturaleza homóloga. Tiene efectos similares a una ley, pues se convierte en una regla preceptiva común que alcanza a todos los justiciables y a los poderes públicos. Aparece como una herramienta técnica que facilita la ordenación y coherencia de la jurisprudencia; $y$, por otro, expone el poder normativo del Tribunal Constitucional dentro del marco de la Constitución, el Código Procesal Constitucional y su Ley Orgánica (...)"."

En ese contexto, el uso del precedente se sustenta en las siguientes condiciones:

a) Existencia de relación entre caso y precedente vinculante. En ese sentido, la regla que con efecto normativo el Tribunal Constitucional decide externalizar como vinculante, debe ser necesaria para la solución del caso planteado. El Tribunal Constitucional no debe fijar una regla so pretexto de solución de un caso, si en realidad ésta no se encuentra ligada directamente con la solución del mismo.

b) La decisión del Tribunal Constitucional de establecer que un caso contiene reglas que se proyectan para el futuro como precedente vinculante se encuentra sujeta a que exista una decisión final; vale decir, que haya puesto fin al proceso; es decir, que dicha decisión contenga autoridad de cosa juzgada. Más aun, dicha decisión final debe concluir con un pronunciamiento sobre el fondo; es decir, estimándose o desestimándose la demanda. La consagración de la cosa juzgada comporta que la decisión devenga en irrevocable e inmutable. c) El establecimiento de un precedente vinculante no debe afectar el principio de respeto a lo ya decidido o resuelto con anterioridad a la expedición de la sentencia que contiene un precedente vinculante; vale decir, no debe afectar las situaciones jurídicas que gocen de la protección de la cosa juzgada. Por ende, no puede impedir el derecho de ejecución de las sentencias firmes, la intangibilidad de lo ya resuelto y la inalterabilidad de lo ejecutado jurisdiccionalmente. Dicha restricción también opera en el caso que el Tribunal Constitucional, al amparo de lo previsto en la parte in fine del artículo VII del Título Preliminar del Código Procesal Constitucional, resuelva apartarse de un precedente y sustituirlo por otro. Lo anteriormente expuesto debe ser concordado con lo previsto en los artículos $74^{\circ} \mathrm{y}$ $103^{\circ}$ de la Constitución, y $83^{\circ}$ del Código Procesal Constitucional, cuando de por medio existe una declaración de inconstitucionalidad.

En consecuencia, el precedente vinculante constituye una herramienta no sólo para dotar de mayor producibilidad a la justicia constitucional, sino también para optimizar la defensa de los derechos fundamentales, expandiendo los efectos de la sentencia en los procesos de tutela de derechos fundamentales.

\section{RESPECTO A LAS SENTENCIAS INTERPRETATIVAS}

Con relación a las sentencias interpretativas, el Tribunal Constitucional ha sostenido lo siguiente:

\subsection{Los límites de las sentencias interpretativas}

60. Aunque la labor interpretativa e integrativas de este Tribunal se encuentra al servicio de la optimización de los principios y valores de la Constitución, tiene también en las disposiciones de ésta a sus límites. Y es que, como resulta evidente que este Tribunal Constitucional sea el supremo intérprete de la Constitución (articulo 2010 y 2020 de la Constitución y 10 de la Ley No 28301 - Ley Orgánica del Tribunal Constitucional-), en nada relativiza su condición de poder constituído,

\footnotetext{
${ }^{28}$ Párrafo 27, 28 y 31 de la STC 0024-31-AI/TC emitida por el Tribunal Constitucional el 10 de octubre de 2005.
} 
sometido, como todos, a los límites establecidos en la Constitución.

61. Así como la fuerza normativa de la Constitución (artículo 51) y las responsabilidades constitucionales con las que deben actuar los poderes públicos (artículo $45^{\circ}$ de la Constitución) son las que, en última instancia, otorgan fundamento constitucional al dictado de las sentencias interpretativas e integrativas del Tribunal Constitucional, son, a su vez, las que limitan los alcances y oportunidad de su emisión. De esta manera, y sin ánimo exhaustivo, los límites al dictado de las sentencias interpretativas o integrativas denominadas "manipulativas" (reductoras, aditivas, sustitutivas, y exhortativas) son, cuando menos, los siguientes:

a) En ningún caso vulnerar el principio de separación de poderes, previsto en el artículo $43^{\circ}$ de la Constitución. Esto significa que, a diferencia de la competencia del Congreso de la República de crear derecho ex Novo dentro del marco constitucional (artículos $90^{\circ}$ y $102^{\circ}$, inciso a, de la Constitución), las sentencias interpretativas e integrativas sólo pueden concretizar una regla de derecho a partir de una derivación directa de las disposiciones de la Constitución e incluso de las leyes dictadas por el Parlamento "conforme a ellas". En suma, deben tratarse de sentencias cuya concretización de normas surja de una interpretación o analogía secundan constituciones.

b) No cabe dictarlas cuando, advertida la inconstitucionalidad en la que incurra la ley impugnada, y a partir de una adecuada interpretación del texto constitucional y del análisis de la unidad del ordenamiento jurídico, exista más de una manera de cubrir el vacío normativo que la declaración de inconstitucionalidad pueda generar. En dichos casos, corresponde al Congreso de la República y no a este Tribunal optar por alguna de las distintas fórmulas constitucionales que permitan reparar la inconstitucionalidad, en la que la ley cuestionada incurre, por lo que sólo compete a este Tribunal apreciar si ella es declarada de inmediato o se le concede al Parlamento un plazo prudencial para actuar conforme a sus competencias $y$ atribuciones.

c) Sólo cabe dictarlas con las responsabilidades exigidas por la Carta Fundamental (artículo $45^{\circ}$ de la Constitución). Es decir, sólo pueden emitirse cuando sean imprescindibles a efectos de evitar que la simple declaración de inconstitucionalidad residente en la ley impugnada, genere una inconstitucionalidad de mayores alcances $y$ perversas consecuencias para el Estado social y democrático de derecho.

d) Sólo resultan legitimas en la medida de que este Colegiado argumente debidamente las razones $y$ los fundamentos normativos constitucionales que, a luz de lo expuesto, justifiquen su dictado; tal como, por lo demás, ha ocurrido en las contadas ocasiones en las que este Tribunal ha debido acudir a su emisión (STC 0010-2002-Al, 0006-2003-Al, 0023-2003-Al, entre otras). De este modo, su utilización es excepcional, pues, como se dijo, sólo tendrá lugar en aquellas ocasiones en las que resulten imprescindibles para evitar que se desencadenen inconstitucionales de singular magnitud.

e) La emisión de estas sentencias requiere de la mayoría calificada de votos de los miembros de este Colegiado. Estos criterios constituyen precedentes vinculantes para todos los poderes públicos, de conformidad con lo establecido en el artículo VII del Código Procesal Constitucional". ${ }^{29}$

\section{EXISTE DIFERENCIAS ENTRE LA FACULTAD LEGISLATIVA DEL CONGRESO Y LA FACULTAD DEL TRIBUNAL CONSTITUCIONAL COMO LEGISLADOR POSITIVO?}

Debido a que no queda ninguna duda que el Tribunal Constitucional ejerce funciones de legislador positivo, cabe precisar que ésta no guarda semejanza con la facultad legislativa del Congreso.

\footnotetext{
${ }^{29}$ Fundamentos 60-61 de la STC 0030-2005-Al emitida por el Tribunal Constitucional el 02 de febrero de 2006.
} 
Ello, si bien las sentencias interpretativas, la jurisprudencia vinculante y la doctrina jurisprudencial implican el ejercicio de facultades legislativas, estas son en forma limitada $y$ disminuida; pues el Tribunal Constitucional cuando expide este tipo de sentencias no elige ni escoge la mejor interpretación a partir del criterio de "oportunidad" y de "conveniencia", sino aquella que responda a una exigencia constitucional. ${ }^{30}$

En la medida que el Tribunal Constitucional no es un órgano de decisión política sino de control de la constitucionalidad, no le corresponde a éste juzgar la oportunidad ni la conveniencia de una norma, sino, sólo si ésta se ajusta a la Constitución o nó. Por tanto, el Tribunal Constitucional no actúa teniendo como lineamiento la oportunidad ni conveniencia política, a diferencia de los órganos políticos como el Congreso o el Poder Ejecutivo.

No obstante, los excesos del Tribunal Constitucional 0 , mejor dicho, el uso desmesurado de su poder como Supremo Intérprete de la Constitución, ha conllevado a que no exista -para efectos prácticos- diferencias significativas entre la facultad legislativa del Congreso y la del propio Tribunal Constitucional y, por estos excesos es que dichas facultades tienden a ganarse implacables enemigos.

\section{BIBLIOGRAFÍA}

DIAZ REVORIO, Francisco Javier. La Constitución Abierta y su Interpretación. Palestra Editores. Lima. 2004.P.286.

RUBIO CORREA, Marcial. La interpretación de la Constitución según el Tribunal Constitucional. Pontificia Universidad Católica del Perú. Fondo Editorial. Lima. 2005. P. 455.

RUIZ MOLLEDA, Juan Carlos. .Es el Tribunal Constitucional un Legislador Positivo?. En: Justicia Viva Mail. En: http//www.justiciaviva.org.pe/justiciamail/jmo299.htm

\section{Referencias Jurisprudenciales}

- Tribunal Constitucional Peruano, Sentencia del 08/04/2003, expediente 0578-2003AATC

- Tribunal Constitucional Peruano, Sentencia del 03/04/2003, expediente 0010-2002AITC

- Tribunal Constitucional Peruano, Sentencia del 01/12/2003, expediente 006-2003AITC

- Tribunal Constitucional Peruano, Sentencia del 29/04/1997, expediente 0018-1996 ITC

- Tribunal Constitucional Peruano, Sentencia del 06/02/2005, expediente 0004-2004

- Tribunal Constitucional Peruano, Sentencia del 07/11/2002, expediente 2409-2002

- Tribunal Constitucional Peruano, Sentencia del 13/04/2005, expediente 0054-2004

- Tribunal Constitucional Peruano, Sentencia del 31/12/2004, expediente 004-2004

- Tribunal Constitucional Peruano, Sentencia del 13/02/2007, expediente 006-2006

- Tribunal Constitucional Peruano, Sentencia del 28/10/2005, expediente 0026-2005

- Tribunal Constitucional Peruano, Sentencia del 08/08/2005, expediente 0020-2007

- Tribunal Constitucional Peruano, Sentencia del 03/09/2007, expediente 03283-2007

- Tribunal Constitucional Peruano, Sentencia del 10/10/2005, expediente 002431

- Tribunal Constitucional Peruano, Sentencia del 02/02/2006, expediente 0030-2005

${ }^{30}$ RUIZ MOLLEDA, Juan Carlos. .Es el Tribunal Constitucional un Legislador Positivo?. Consorcio Justicia Viva.

http//www.justiciaviva.org.pe/justiciamail/jm0299.htm. 